\title{
Process standardization for alginate encapsulation of potentially probiotic Pediococcus pentosaceus DM101

Jithu Rappai ${ }^{1}$, A.K. Beena ${ }^{2}$, Ligimol James ${ }^{3}$ and

V. Aparna Sudhakaran ${ }^{3}$

Department of Dairy Microbiology

College of Dairy Science and Technology,

Mannuthy, Thrissur, Kerala-680651, India.

Kerala Veterinary and Animal Sciences University.

Citation: Rappai, J., Beena, A.K., James, L. and Aparna, S.V. 2021. Process standardization for alginate encapsulation of potentially probiotic Pediococcus pentosaceus DM101. J. Vet. Anim. Sci. 52(2): 196-199. DOI: https://doi.org/10.51966/jvas.2021.52.2.196-199

Received:23.12.2020

Accepted:26.01.2021

Published:01.06.2021

\begin{abstract}
The main objective of this study was to standardise the procedure for encapsulation of potentially probiotic breast milk isolate Pediococcus pentosaceus DM101 using sodium alginate by extrusion method. The encapsulation parameters were optimized by comparing the encapsulation efficiency obtained with varying concentration of sodium alginate $(0.5,1.0,1.5$ and $2.0 \%)$, calcium chloride (0.05, 0.1 and $0.2 \mathrm{M})$ and gelling time (5, 10, 20 and 30 minutes). Encapsulation efficiency was ascertained by finding the survival percentage after exposing the encapsulated cells to acid stress ( $\mathrm{pH} 2.0$ for 3h). Encapsulation carried out using two per cent sodium alginate and $0.1 \mathrm{M}$ $\mathrm{CaCl}_{2}$ following 20 min gelling time was found to confer maximum protective effect. Encapsulation efficiency of alginate beads prepared under optimized conditions was found to be $81.37 \pm 2.44$ per cent. The results endorse alginate encapsulation as a means to confer a protective shielding effect thereby facilitating effective probiotic delivery.
\end{abstract}

Key-words: Probiotic, Optimization, Sodium alginate, Pediococcus pentosaceus

The consumption of probiotics in adequate amounts, provide health benefits to the host by improving their intestinal microbial balance. The survivability and functionality of probiotics in food products are very much dependent on the processing methods adopted, additives used, storage conditions and intrinsic parameters of the food product. Though inclusion of probiotic bacteria in food products does enhance their value as functional foods, ensuring the stipulated number of cells

*Part of M.tech thesis submitted by the first author to the Kerala Veterinary and Animal Sciences University, Pookode, Wayanad, Kerala

1. M. Tech scholar

2. Professor and Head, and corresponding author email:akbeena@kvasu.ac.in Ph:9446293686

3. Assistant Professor

Copyright: ( 2021 Jithu Rappai et al. This is an open access article distributed under the terms of the Creative Commons Attribution 4.0 International License (http://creativecommons.org/licenses/by/4.0/), which permits unrestricted use, distribution, and reproduction in any medium, provided the original author and source are credited.

196 Process standardization for alginate encapsulation of potentially.. 
is a challenging in commercial food products. Food matrices and storage conditions have a direct and significant impact on viability of cells and so there is a requirement for a compatible system to ensure the required number of cells at the time of consumption. Apart from the availability of the viable probiotic cells at the time of consumption, the bioavailability of these cells within the host also must be given due consideration. A compatible food system that will safeguard the probiotic cells within the product as well as during gastrointestinal transit will be very much advantageous. Encapsulation is a promising technique for protecting probiotic bacteria in adverse conditions posed within the product prior to consumption as well as after consumption within the gastrointestinal tract. Alginate along with calcium and barium is frequently used for encapsulation of biologically active components as it forms a stable gel by cross linking with divalent cations as in the egg-box model proposed by Pankongadisak et al. (2014). Process optimization of alginate encapsulation will ensure effective probiotic delivery at the target site thereby improving health benefits. The encapsulation parameters chosen for optimization of encapsulation process were sodium alginate concentration, $\mathrm{CaCl}_{2}$ concentration and gelling time.

The probiotic microorganism selected for this study was Pediococcus pentosaceus DM101 (NCBI accession number: MK774704), a human milk isolate stored in the culture stock of Department of Dairy Microbiology. This isolate with a log phase of $19 \mathrm{~h}$ at $37^{\circ} \mathrm{C}$ has been reported to possess remarkable acid tolerance, bile tolerance and good autoaggregation potential (67.9 per cent) during its probiotic characterization. With an IC 50 value of $20.78 \mathrm{mg} / \mathrm{ml}$, the antioxidant activity of the isolate has also been established (Rappai et al., 2020). The freshly activated cells of Pediococcus pentosaceus DM101 in the log phase (19h) were harvested by subjecting to refrigerated centrifugation (Velocity 18R Refrigerated, Dyna MICO) at 12000rpm for $10 \mathrm{~min}$ at $4^{\circ} \mathrm{C}$. The cell pellet obtained from $1 \mathrm{ml}$ De Man Rogosa and Sharpe (MRS) broth was dispensed in minimum quantity of sterile distilled water prior to mixing with encapsulating solution. Encapsulation of bacteria was done in sodium alginate by extrusion method. The highly concentrated cell suspension (from $1 \mathrm{ml}$ culture broth) with a viable count of $10^{9}$ cells was mixed with one milliliter of sodium alginate solution. This mixture was then carefully added drop by drop using a sterile dropper (diameter $2 \mathrm{~mm}$ ) into sterilized $\mathrm{CaCl}_{2}$ solution (Hi-media) maintained at a temperature of $29^{\circ} \mathrm{C}$. Upon contact with the solution, spherical gels were formed immediately. The beads so formed were collected, washed with 0.1 per cent peptone water and stored at $4^{\circ} \mathrm{C}$ till further assays.

The optimization of encapsulation parameters were done by finding the survival percentage of cells in beads prepared by varying encapsulation parameters: concentration of alginate $(0.5,1.0,1.5$ and 2.0 per cent), concentration of $\mathrm{CaCl}_{2}(0.05,0.1$ and $0.2 \mathrm{M})$ and gelling time $(5,10,20$ and $30 \mathrm{~min})$. Survival percentage was determined by comparing the initial number of viable cells and number of surviving cells in the beads after exposure to $\mathrm{pH}$ 2.0/3h in phosphate buffered saline(PBS) (Kiran et al., 2015).

Survival percent $=\left\{\frac{\log \mathrm{CFU} / \mathrm{ml} \text { at } 3 \mathrm{~h}^{*} 100}{\log \mathrm{CFU} / \mathrm{ml} \text { at } \mathrm{Oh}}\right\}$

The strategy of varying one parameter at a time, keeping others unaltered was employed. Once a particular parameter was found to show maximum survival percent, that parameter was fixed for designing the next trial for optimization. In all experiments free cells was served as control. Accordingly after finalizing the concentration of alginate, concentration of $\mathrm{CaCl}_{2}$ and then the gelling time were fixed. All the beads prepared with the cells from one milliliter broth constituted the sample for plating. The beads were aseptically homogenized in normal saline using sterile mortar and pestle to ensure complete release of the cells. Appropriate dilutions of this were pour plated in MRS agar and incubated at $37^{\circ} \mathrm{C}$ for $48 \mathrm{~h}$ (Harrigan, 1998). The efficiency of encapsulation was evaluated by finding the encapsulation yield (EY). Encapsulation efficiency was evaluated by looking into the number of viable cells in the encapsulate to that of master culture. This was done immediately after encapsulation. 
$E Y=\left(N / N_{0}\right)^{*} 100$

Where $\mathrm{N}_{0}$ is the number of viable bacteria in culture and $\mathrm{N}$ is the number of viable bacteria in beads.

The observations indicated that the survivability improved progressively with increase in alginate concentration. With the fixed gelling time of $30 \mathrm{~min}$ and $0.1 \mathrm{M} \mathrm{CaCl}_{2}$ concentrations, the percentage survival of encapsulated Pediococcus pentosaceus DM101 with varying alginate concentrations: $0.5,1.0,1.5$ and 2.0 per cent were 59.74, $51.31,57.50$, and 91.97 per cent respectively. This observation is in agreement with the reports of Mandal et al. (2006). Low alginate concentration yield beads with poor gel strength that are less capable of withstanding simulated gastric conditions. Such beads have a sticky nature and are difficult to handle (Jankowski et al., 1997). But increasing the alginate concentration beyond a limit makes the bead preparation difficult due to its high viscosity (Belalia and Djelali, 2014)

In this study, an alginate concentration of two per cent was sufficient to maintain a survivability of more than 90 per cent. The optimization of strength of $\mathrm{CaCl}_{2}$ solution was done by keeping alginate concentration and gelling time constant at two percent and $30 \mathrm{~min}$ respectively. The survivability of encapsulated $P$. pentosaceus DM101 at $\mathrm{CaCl}_{2}$ concentrations; $0.05,0.1$, and $0.2 \mathrm{M}$ were 60.24 , 66.91 and 56.78 per cent respectively. Calcium chloride $(0.1 \mathrm{M})$ yielded maximum number of survivors in the experimental conditions followed in our study. From the observations, it can be inferred that influence of $\mathrm{CaCl}_{2}$ concentration is comparatively less than that of alginate concentration on the viability of the encapsulated cells. Tanaka et al. (1984) also reported that the effect of $\mathrm{CaCl}_{2}$ on the diffusion characteristics of the beads is quite negligible. In our study more than 90 per cent survivability was observed for a gelling time of both 20 and $30 \mathrm{~min}$. Percentage survivors were more or less same for 5 and 10 min of gelling time. The maximum survivability of 98.25 per cent was obtained when gelling time was $20 \mathrm{~min}$. Chandramouli et al. (2004) opined to increase the gelling time for improving the number of viable cells in encapsulates, when hardened in $0.1 \mathrm{M} \mathrm{CaCl}_{2}$.

\section{Summary}

The encapsulation of Pedicoccus pentosaceus DM101 was optimized with two per cent alginate, $0.1 \mathrm{M} \mathrm{CaCl}_{2}$ and 20 min gelling time. The encapsulates/ beads prepared following the optimized procedure exhibited an encapsulation efficiency of $81.37 \pm 2.44$ per cent. Alginate concentration was found to have more influence on the encapsulation efficiency than other parameters. The survivability of encapsulated cells in simulated gastric $\mathrm{pH}$ endorses the efficacy of encapsulation technique to achieve targeted delivery of probiotics. Process sophistication of the conventional techniques is essential for improving the encapsulation efficiency and further in-vivo tests are needed to confirm the benefits of functional foods developed using bioactive components in the encapsulated form.

\section{References}

Belalia, F. and Djelali, N. 2014. Rheological properties of sodium alginate solutions. Rev. Roum. Chim. 59(2): 135-145

Chandramouli, V., Kailasapathy, K., Peiris, P. and Jones, M. 2004. An improved method of microencapsulation and its evaluation to protect Lactobacillus spp. in simulated gastric conditions. J. Microbiol. Meth. 56(1): 27-35.

Harrigan, W.F. 1998. Laboratory Methods in Food Microbiology. Academic Press, $532 p$

Jankowski, T., Zielinska, M. and Wysakowska, A. 1997. Encapsulation of lactic acid bacteria with alginate/starch capsules. Biotechnol. Tech. 11(1): 31-34.

Kiran, F., Mokran, I. M. and Osmanagaoglu, O. 2015. Effect of encapsulation on viability of Pediococcus pentosaceus OZF during its passage through the gastrointestinal tract model. Curr. Microbiol. 71: 95-105 
Mandal, S., Puniya, A.K. and Singh, K. 2006. Effect of alginate concentrations on survival of microencapsulated Lactobacillus casei NCDC-298. Int. Dairy J. 16(10): 1190-1195

Pankongadisak, P., Ruktanonchai, U.R., Supaphol, P. and Suwantong, O. 2014. Preparation and characterization of silver nanoparticles-loaded calcium alginate beads embedded in gelatin scaffolds. AAPS Phar. Sci. Tech. 15: 1105-1115
Rappai, J., Beena, A.K., James, L. and Sudhakaran, V.A. 2020. Probiotic characterization of lactic acid bacteria isolated from human milk. The Pharma Innovation Journal. 9(7): 383-388

Tanaka, H., Matsumura, M. and Veliky, I.A. 1984. Diffusion characteristics of substrate in calcium alginate beads. Biotechnol. Bioeng. 26: 53-58 